Albert Messiah

Quantenmechanik

Band 1 



\section{Albert Messiah}

\section{Quantenmechanik}

Band 1

Aus dem Französischen übersetzt von Joachim Streubel

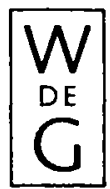

Walter de Gruyter · Berlin · New York 1976 
Titel der französischen Originalausgabe: Albert Messiah „Mécanique Quantique”, Tome 1

ㄷ 1969 by Dunod, Editeur, Paris

\section{Autor}

Albert Messiah

Professor am Institut National des

Sciences et Technique Nucléaires

Obersetzer

Joachim Streubel

Diplomphysiker

Dieser Band enthält 38 Abbildungen.

CIP-Kurztitelaufnahme der Deutschen Bibliothek

Messiah, Albert

Quantenmechanik. - Berlin, New York: de Gruyter.

Einheitssacht.: Mécanique quantique (dt.).

Bd. 1. - 1. Aufl. - 1976.

ISBN 3-11-003686-X

Zweiter, unveränderter Nachdruck 1981

(C) Copyright 1976 by Walter de Gruyter \& Co., vormals G. J. Göschen'sche Verlagshandlung, J. Guttentag, Verlagsbuchhandlung Georg Reimer, Karl J. Trübner, Veit \& Comp., Berlin 30.

Alle Rechte, insbesondere das Recht der Vervielfältigung und Verbreitung sowie der Übersetzung, vorbehalten. Kein Teil des Werkes darf in irgendeiner Form (durch Photokopie, Mikrofilm oder ein anderes Verfahren) ohne schriftliche Genehmigung des Verlages reproduziert oder unter Verwendung elektronischer Systeme verarbeitet, vervielfältigt oder verbreitet werden. Printed in Germany.

Satz: Verena Boldin, Aachen; Druck: Karl Gerike, Berlin; Bindearbeiten: Buchgewerbe GmbH Liideritz \& Bauer, Berlin. 